\title{
Attitude, knowledge and experience of hospital pharmacists with pharmacovigilance in a region in Saudi Arabia: a cross-sectional study
}

\author{
Fawaz Alharbi ${ }^{1 *}$, Anas Bahnassi ${ }^{2}$ and Wedad Alonazie ${ }^{3}$ \\ ${ }^{1}$ Drug Information and Poison Center, Alansar Hospital, ${ }^{2}$ Department of Clinical and Hospital Pharmacy, College of Pharmacy, \\ Taibah University, ${ }^{3}$ Pharmaceutical Care Department, Alansar Hospital, Al Madinah Al Munawarah, Saudi Arabia \\ *For correspondence: Email: FaAbAlharbi24@moh.gov.sa
}

Received: 23 May 2016

Revised accepted: 31 July 2016

\begin{abstract}
Purpose: To assess hospital pharmacists' knowledge of, attitude to, and experience with pharmacovigilance and adverse drug reactions (ADRs) in Al Madinah Al Munawarah region, Saudi Arabia.

Methods: A cross-sectional study was conducted from April - June 2015 among hospital pharmacists using a self-administered questionnaire. All pharmacists working in government hospitals and primary care centers in Al Madinah Al Munawarah region were targeted to participate in the study. A total of 130 pharmacists were included in the study. Data analysis was conducted using the Statistical Package for Social Sciences, version 20.

Results: The response rate to the survey was $79 \%$ out of 103 pharmacists. In terms of knowledge about pharmacovigilance, only 56 (54.4\%) correctly identified WHO definition of ADRs, while 53 (51.5 $\%)$ of the pharmacists correctly defined pharmacovigilance. Regarding pharmacists' experience with $A D R$ reporting, less than half $(N=46,44.7 \%)$ said they have made a suspected $A D R$ report and slightly less than half of the pharmacists (50, $48.5 \%)$ said they are familiar with Saudi Food and Drug Authority (SFDA) system of suspected ADR reporting. The majority of the pharmacists $(N=95,92.2 \%)$ believed that patient safety is the most important goal of suspected ADR reporting. The most common barrier to $A D R$ reporting was lack of pharmacovigilance training $(N=48,46.6 \%)$.

Conclusion: Pharmacists had insufficient knowledge of, but positive attitude toward pharmacovigilance and ADR reporting. Lack of pharmacovigilance training has been identified as the major barrier to ADR reporting.
\end{abstract}

Keywords: Hospital pharmacists, Pharmacovigilance, Adverse drug reactions (ADRs), Attitude, Knowledge

Tropical Journal of Pharmaceutical Research is indexed by Science Citation Index (SciSearch), Scopus, International Pharmaceutical Abstract, Chemical Abstracts, Embase, Index Copernicus, EBSCO, African Index Medicus, JournalSeek, Journal Citation Reports/Science Edition, Directory of Open Access Journals (DOAJ), African Journal Online, Bioline International, Open-J-Gate and Pharmacy Abstracts

\section{INTRODUCTION}

As defined by the World Health Organization (WHO) "Pharmacovigilance is the science and activities relating to the detection, assessment, understanding and prevention of adverse effects or any other drug-related problems" [1]. In Saudi Arabia, the Saudi Food and Drug Authority
(SFDA) is the main authority that is responsible for the safety of food and drugs for humans and animals [2]. The safety of post-marketed medications in Saudi Arabia is monitored by the National Pharmacovigilance and Drug Safety Center through the Saudi Adverse Event Reporting System (SAERS) [3]. Healthcare professionals, patients, and drug manufacturers 
should submit their reports about any suspected adverse drug reactions (ADRs) to the SAERS using special forms designed by the National Pharmacovigilance and Drug Safety Center.

ADRs are the main cause of hospital admissions [4-7]. The early detection and assessment of ADRs through raising the awareness of healthcare professionals about the necessity and advantages of reporting to improve patient safety are highly encouraged [8]. However, several factors have been identified as discouraging ADR reporting. A poor understanding and lack of knowledge of the ADR reporting process, the unavailability of ADR reporting forms, the misconception that ADR reporting is the responsibility of physicians, and the fear of liability have been reported as factors discouraging ADR reporting in Saudi Arabia [911].

A recent qualitative study has identified several challenges to pharmacovigilance, such as a lack of knowledge of the significance of ADR reporting, workloads, and a lack of collaboration between regulatory bodies and the hospitals [12]. Internationally, other challenges exist, including uncertainty about whether the event is drugrelated, the underestimation of ADR seriousness, being too busy to report an ADR, and a lack of awareness of the process of ADR reporting [1318].

To improve ADR reporting, it is essential to assess the baseline knowledge, attitudes, and practices of hospital pharmacists regarding pharmacovigilance. Therefore, this study was conducted to evaluate hospital pharmacists' knowledge of, attitudes toward, and experiences with ADR reporting and pharmacovigilance, and they were asked what factors might be helpful to encourage ADR reporting.

\section{METHODS}

\section{Study design and setting}

This was a cross-sectional study conducted from April-June 2015 among 103 pharmacists working in 11 government hospitals and primary care centers in the Al Madinah Al Munawarah region, Saudi Arabia. Of these hospitals, nine were affiliated to Saudi Ministry of Health, one to National Guard and another to Ministry of Defense. Seven were primary care centres affiliated to Ministry of Health, while three were medical centres; of the latter, two were affiliated to Ministry of Education and the second to Ministry of Interior in Al Madinah Al Munawarah region, Saudi Arabia.

\section{Study tool}

The study questionnaire consisted of six sections, including demographic information, knowledge, experience, attitudes, barriers, and factors encouraging ADR reporting. Pharmacists' knowledge about ADRs was assessed by asking them to choose the correct definition of an ADR according to the WHO, to define pharmacovigilance in their own words, and to identify the differences between ADRs and medication errors. Pharmacists' experiences with ADR reporting were assessed by asking eight related questions. Pharmacists' attitudes toward ADR reporting were assessed by asking three multiple-choice questions. The questions include the most important goals of reporting suspected ADRs and motivations to report ADRs. Barriers to ADR reporting were assessed by providing a list of barriers and by asking pharmacists to choose one or more answers. An open-ended question was asked of the pharmacists regarding the factors encouraging ADR reporting. The content validity of the questionnaire was determined by three qualified pharmacists.

\section{Data collection}

All pharmacists working in government hospitals and primary care centers in the Al Madinah Al Munawarah region were targeted to participate in this study. One of the authors visited each hospital, explained the aims of the study to the pharmacists, and thereafter asked them to participate in the study. Those who agreed to participate in the study were given a copy of the self-administered questionnaire to be completed and returned. The participants' identities were not revealed to anybody, nor were their names asked to be included in the questionnaire to protect the confidentiality of the information. Informed consent was obtained from each participant. In addition, participants were informed that participation in the study is voluntary, that the purpose of the study is not to evaluate their institution, and that no authority will have access to their individual responses.

\section{Ethical approval}

Ethical approval (ref. no. 68 /27-1-1436) was obtained from Research and Ethics Committee of the General Directorate of Health Affairs, Al Madinah Region.

\section{Data analysis}

Descriptive statistics were used to analyze the data (frequency and percentages). Statistical analysis was performed using Statistical 
Package for Social Sciences (SPSS) for Windows (version 20.0).

\section{RESULTS}

In total, 130 pharmacists working in government hospitals and primary care centers in the $\mathrm{Al}$ Madinah Al Munawarah region were approached to participate in the study, and 103 (79\%) responded to the survey. The majority of the pharmacists were working for Ministry of Health $(\mathrm{MOH})$ hospitals $(82,79.6 \%$ ) (Table 1). Half of the hospitals $(52,50.5 \%)$ had the Saudi Central Board of Accreditation for Healthcare Institutions (CBAHI). However, only $30(29.1 \%)$ had Joint Commission International $(\mathrm{JCl})$ accreditation.

Table 1: Demographic characteristics of the participating pharmacists

\begin{tabular}{cc}
\hline Variable & N (\%) \\
\hline Pharmacist's affiliation & \\
Ministry of Health & $82(79.6)$ \\
Ministry of Defense & $7(6.8)$ \\
National Guard & $10(9.7)$ \\
Other & $4(3.9)$ \\
Gender & \\
Male & $78(75.7)$ \\
Female & $25(24.3)$ \\
Nationality & \\
Saudi & $83(80.6)$ \\
Non-Saudi & $20(19.4)$ \\
Age & \\
20-30 & $51(49.5)$ \\
31-40 & $35(34)$ \\
41-50 & $15(14.6)$ \\
>50 & $2(1.9)$ \\
BPharm & \\
PharmD & $72(69.9)$ \\
MSc & $19(18.4)$ \\
PhD & $7(6.8)$ \\
Position of pharmacist & $5(4.9)$ \\
Staff & \\
Supervisor & $53(51.5)$ \\
Assistant director & $31(30.1)$ \\
Director & $4(3.9)$ \\
Other & $12(11.7)$ \\
& $3(2.9)$ \\
\hline
\end{tabular}

The majority of the pharmacists were Saudi nationals and $51(49.5 \%)$ were in the age group of 20-30 years old. As well, 72 (69.9\%) pharmacists had a BPharm degree. Regarding the positions of the pharmacists, the majority were staff pharmacists $(53,51.5 \%)$ and supervisors $(31,30.1 \%)$. The participants had an average of 7.8 years of experience (Table 1 ).

Regarding pharmacists' knowledge about pharmacovigilance, only 56 (54.4\%) could correctly identify the WHO definition of ADRs, while $53(51.5 \%)$ of the pharmacists could correctly define the term pharmacovigilance in their own words and $66 \quad(64.1 \%)$ could differentiate between medication errors and ADRs (Table 2).

Regarding pharmacists' experience with ADR reporting, $46(44.7 \%)$ said that they have made a suspected ADR report, 34 (33\%) of whom made the report in their current location of practice. Slightly less than half of the pharmacists $(50,48.5 \%)$ said that they are familiar with the SFDA system of suspected ADR reporting. However, when asked how they learned about the SFDA, $13(12.6 \%)$ learned from SFDA officials, $5(4.9 \%)$ learned from a colleague, 17 (16.55\%) learned from $\mathrm{MOH}$ official memos, one $(1 \%)$ learned from the media, and $14(13.6 \%)$ learned from the SFDA website (Figure 1). As well, $67(65 \%)$ said that they are familiar with the policy and procedures for reporting ADRs in their hospitals, 61 (59.2\%) of whom said they have easy access to the policy and procedures and can easily find the form to report suspected ADRs. However, of these, only $55(53.4 \%)$ were aware of the location where they should send the report if they were to encounter a suspected ADR (Table 3).

The majority of the pharmacists ( $N=95,92.2 \%$ ) believed that patient safety is the most important goal of suspected ADR reporting (Figure 2). Suspected ADR reporting was considered a professional obligation by 54 (52.4\%), a means for pharmacists to get closer insight into drugrelated problems by $69(67 \%)$, a duty of the prescribing physician by $28(27.2 \%)$, and a duty of the manufacturer by $16(15.5 \%)$.

Table 2: Knowledge of hospital pharmacists about Pharmacovigilance

\begin{tabular}{lcc}
\hline Variable & $\begin{array}{c}\text { Correct } \\
\text { answer } \\
\mathbf{N}(\%)\end{array}$ & $\begin{array}{c}\text { Incorrect } \\
\text { Answer } \\
\mathbf{N}(\%)\end{array}$ \\
\hline Definition of ADRs according to the World Health Organization & $56(54.4)$ & $47(45.6)$ \\
Definition of pharmacovigilance & $53(51.5)$ & $50(48.5)$ \\
Knowledge of the difference between ADRs and medication errors & $66(64.7)$ & $37(36.3)$ \\
\hline
\end{tabular}


Table 3: Experience with ADR reporting

\begin{tabular}{lcc}
\hline Variable & Yes & $\begin{array}{c}\text { No } \\
\text { N (\%) }\end{array}$ \\
\hline Over the course of your practice, have you made a suspected ADR report? & $46(44.7)$ & $57(55.3 \%)$ \\
If the answer to the previous question is "yes," did you make that report in your & $34(33)$ & $69(67)$ \\
current location of practice? & $50(48.5)$ & $53(51.5)$ \\
Are you familiar with the SFDA system of suspected ADR reporting? & $67(65)$ \\
$\begin{array}{l}\text { Are you familiar with the policy and procedures for reporting ADRs in your } \\
\text { hospital? }\end{array}$ & \\
$\begin{array}{l}\text { If the answer to previous question is "yes," do you have easy access to the } \\
\text { policy and procedures, and can you easily find the form to report suspected } \\
\text { ADRs? }\end{array}$ & \\
$\begin{array}{l}\text { If the answer to previous question is "yes," are you aware of where you should } \\
\text { send the report if you were to encounter suspected ADRs? }\end{array}$ & $55(53.4)$ \\
\hline
\end{tabular}

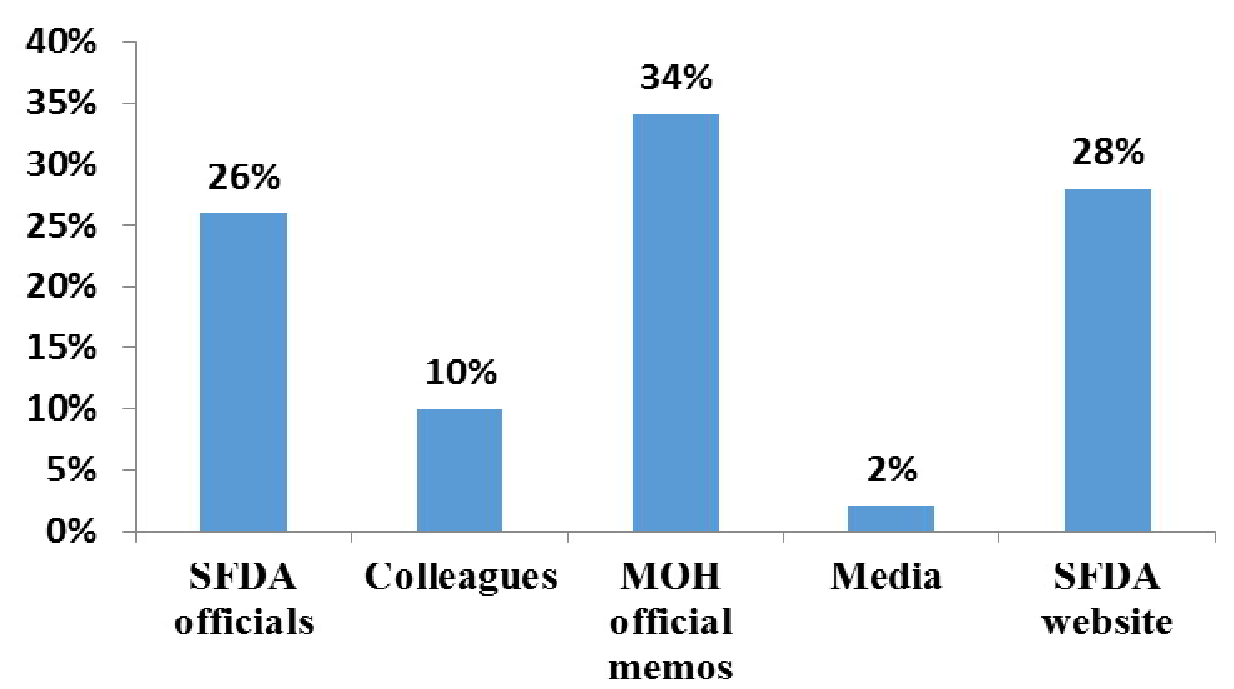

Figure 1: How participants learn't about ADR report

Pharmacists' motivations to report ADRs were associated with a new medication (18, $17.5 \%)$, with a new ADR to an old medication ( $N=23$, $22.3 \%$ ), with the seriousness of the ADR ( $N=$

Table 4: Pharmacists' attitude towards ADR reporting
$41,39.8 \%$ ), with the severity of the ADR ( $\mathrm{N}=$ $34,33 \%)$, and with the frequency of the ADR (N $=24,23.3 \%$ ) (Table 4).

\begin{tabular}{lcc}
\hline Variable & $\begin{array}{c}\text { Yes } \\
\mathbf{N}(\%)\end{array}$ & $\begin{array}{c}\text { No } \\
\mathbf{N}(\%)\end{array}$ \\
\hline $\begin{array}{l}\text { Suspected ADR reporting is considered } \\
\text { A professional obligation of pharmacists }\end{array}$ & $54(52.4)$ & $49(47.6)$ \\
A means for pharmacists to get a closer insight & $69(67)$ & $34(33)$ \\
problems & & $75(72.8)$ \\
A duty of the prescribing physician & $28(27.2)$ & $87(84.5)$ \\
A duty of the manufacturer & $16(15.5)$ & \\
& & \\
What is your motivation to report an ADR? & $18(17.5)$ & $85(82.5)$ \\
Association with a new medication & $23(22.3)$ & $80(77.7)$ \\
A new ADR to an old medication & $41(39.8)$ & $62(60.2)$ \\
The seriousness of the ADR & $34(33)$ & $69(67)$ \\
The severity of the ADR. & $24(23.3)$ & $79(76.7)$ \\
The frequency of the ADR. &
\end{tabular}




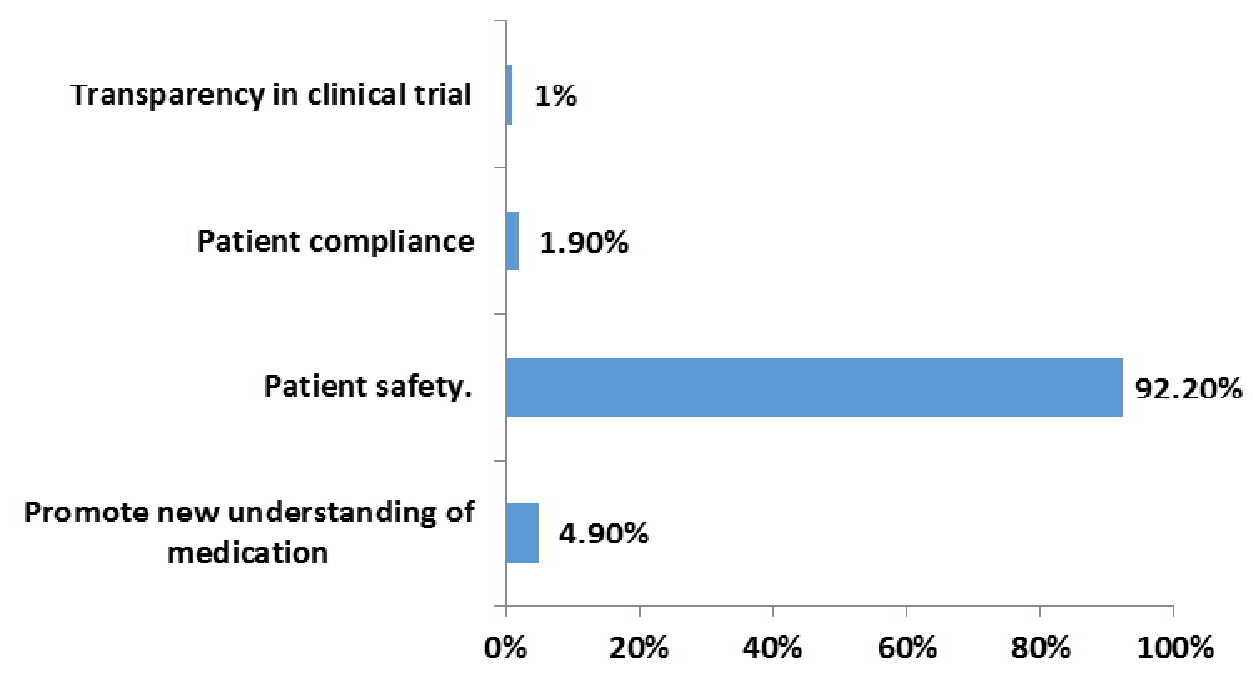

Figure 2: What is the most important goal of suspected ADR reporting?

Barriers to ADR reporting were a lack of access to ADR reporting forms and/or complicated forms $(\mathrm{N}=22,21.4 \%)$, a lack of adequate time to provide ADR reporting ( $\mathrm{N}=33,32 \%$ ), a lack of pharmacovigilance training ( $\mathrm{N}=48,46.6 \%)$, a lack of motivation to report ADRs ( $\mathrm{N}=25,24 \%)$, a sacrificing of reporter image $(\mathrm{N}=7,6.8 \%)$, a fear of liability $(\mathrm{N}=13,12.6 \%)$, and other $(\mathrm{N}=$
10, $9.7 \%$ ) (Table 5).

Several factors that encourage ADR reporting were identified by the participants, including training about pharmacovigilance, increasing community awareness of ADR reporting, and feedback regarding the most recent ADRs reported to the SFDA (Table 6).

Table 5: Barriers to ADR reporting

\begin{tabular}{lcc}
\hline Barrier & Yes & No \\
& $\mathbf{N}(\%)$ & $\mathbf{N}(\%)$ \\
\hline Lack of access to ADR reporting forms/complicated forms & $22(21.4)$ & $81(78.6)$ \\
Lack of adequate time to provide ADR reporting & $33(32)$ & $70(68)$ \\
Lack of pharmacovigilance training & $48(46.6)$ & $55(53.4)$ \\
Lack of motivation to report & $25(24.3)$ & $78(75.7)$ \\
Could sacrifice prescriber/pharmacist image & $7(6.8)$ & $96(93.2)$ \\
Fear of liability & $13(12.6)$ & $90(87.4)$ \\
Other & $10(9.7)$ & $93(90.3)$ \\
\hline
\end{tabular}

Table 6: Factors that encourage ADR reporting

Training of healthcare professionals on the importance of pharmacovigilance and identification and reporting of ADRs.

Organizing campaigns to raise the awareness of the community regarding ADR reporting and give easy access to all community levels, either electronically or manually.

Distribution of regular circular concerning the recent recognized and approved ADRs and the most identified organizations regarding contributions to reporting.

Identifying special healthcare staff to follow ADR identification and reporting.

Motivation of healthcare professionals to report ADRs through CME hours, financial incentives, or holidays.

Providing a safe environment for the person who reported the ADR so no one can make him or her liable or regretful.

Ease the communication between healthcare professionals and the SFDA through social media, such as Facebook, Twitter, and WhatsApp, which are widely used in Saudi Arabia.

Establish patient safety units in the hospitals with the responsibility of ADR reporting and increasing the awareness of healthcare staff about patient safety.

Increase patients' awareness about ADRs and ask them if they experience any ADRs during the patient counseling process. 


\section{DISCUSSION}

This study is the first to assess the knowledge, attitudes, and experiences of hospital pharmacists working in government hospitals and primary care centers regarding pharmacovigilance in the Al Madinah $\mathrm{Al}$ Munawarah region. A self-reported questionnaire was used to ensure that the information obtained in this study is from the pharmacists and that they were not influenced by the researcher. The finding of this study mainly represents the opinions of Saudi pharmacists and they should be targeted for any intervention in the future.

Although few recent studies were conducted in the hospital settings $[19,20]$, the majority of the studies were conducted in community pharmacy settings where most of the pharmacists are expatriates, and the findings of those studies perhaps do not represent Saudi Arabia [9-11].In addition, the studies that were conducted in the hospital settings have targeted all healthcare professionals, and the current study has concentrated on hospital and primary care pharmacists only. Therefore, it is argued that this study presents the knowledge, attitudes, and experiences of the local Saudi pharmacists, and it could help policy makers to understand the current situation of pharmacovigilance practices among Saudi pharmacists.

Regarding the pharmacists' knowledge about the WHO definition of ADRs, $54.4 \%$ had correctly defined the term. In contrast, a previous study reported that $92 \%$ of the community pharmacists in the Eastern region of Saudi Arabia knew the correct definition of ADRs [11]. In addition, about half knew the definition of pharmacovigilance. A recent study from Riyadh reported that $55 \%$ of healthcare professionals did not know the correct definition of pharmacovigilance. In addition, $64 \%$ could not differentiate between a medication error and an ADR. It is obvious there is a lack of knowledge about pharmacovigilance aspects, and urgent interventions are required. Pharmacists are expected to educate patients about patient safety; therefore, to help them do their job efficiently, the hospital authorities in collaboration with the SFDA should undertake training programs to improve hospital pharmacists' knowledge and help them strengthen their role.

The majority of the pharmacists surveyed (55.3 $\%$ ) have never reported ADRs over the course of their practice, and the majority were also unfamiliar with the SFDA ADR reporting system.
This finding is similar to studies from central Saudi Arabia and the Eastern regions, as the majority of the pharmacists were unaware of the ADR reporting system [9-11]. The main reason for this might be the lack of orientation and awareness initiatives from the SFDA, the media, and the $\mathrm{MOH}$. Similar to a previous Saudi study, an overwhelming majority of the pharmacists believed that patient safety is the most important goal of ADR reporting.

\section{Limitations of the study}

The study findings cannot be generalized to all pharmacists in Saudi Arabia. A similar study is required at the national level.

\section{CONCLUSION}

Based on this study's findings, the rules and regulations of SFDA should be improved in $\mathrm{Al}$ Madinah Al Munawarah region. SFDA should strengthen the role of their representatives who should follow up on pharmacovigilance activities, including the dissemination of updates on the safety of medications, the promotion of spontaneous ADR reporting initiatives among pharmacists, as well as organize educational events, including workshops and conferences for pharmacists and other healthcare professionals to explain the role and activities of Saudi Pharmacovigilance Center. The objective of these activities should be to increase the awareness of pharmacists about pharmacovigilance and minimize barriers to ADR reporting. Simple training on the methods of ADR reporting, especially online reporting system of ADRs, might make a big difference in the awareness, reporting rate, and knowledge of pharmacists about spontaneous ADR reporting, as has been observed in other countries.

\section{DECLARATIONS}

\section{Acknowledgement}

The authors would like to thank Drs Mohammad Abutaleb, Salem Almohammadi and Emad AlHarbi for their help with questionnaire validation. Thanks are also due to all participating pharmacists for their valuable contributions to the study.

\section{Conflict of Interest}

No conflict of interest associated with this work. 


\section{Contribution of Authors}

The authors declare that this work was done by the authors named in this article and all liabilities pertaining to claims relating to the content of this article will be borne by them.

\section{REFERENCES}

1. World Health Organization. Pharmacovigilance. [Cited 2014; Accessed 2014 July 12]. Available from URL: http: //www.who. int/medicines/areas/quality_safety/safety_ efficacy/pharmvigi/ en/

2. Saudi Food \& Drug Authority. Vision and Mission Available from URL: http: I/www.sfda.gov.sa/ en/about/Pages/mission.aspx

3. the National pharmacovigilance and Drug Safety center http://www.sfda.gov.sa/en/drug/about/sector_departmen ts/national_pharmacovigilance_center/sector_departme nts_national/Pages/Vigilance_invo.aspx

4. Pirmohamed M, James S, Meakin S, Green C, Scott AK, Walley TJ, Farrar K, Park BK, Breckenridge AM. Adverse drug reactions as cause of admission to hospital: prospective analysis of 18820 patients. BMJ. 2004; 329(7456): 15-19.

5. Patel H, Bell D, Molokhia M, Srishanmuganathan J, Patel M, Car J, Majeed A. Trends in hospital admissions for adverse drug reactions in England: analysis of national hospital episode statistics 1998-2005. BMC Pharmacol Toxicol. 2007; 7(1): 1-11.

6. Lazarou J, Pomeranz BH, Corey PN. Incidence of adverse drug reactions in hospitalized patients: a metaanalysis of prospective studies. JAMA. 1998; 279(15): 1200-1205.

7. Ahmed ME. Drug-associated admissions to a district hospital in Saudi Arabia J Clin Pharm. 1997; 22(1): 61 66.

8. The Lancet (2002) Improving ADR reporting. Lancet 2002; 360: 1435.

9. Mahmoud MA, Alswaida $Y$, Alshammari T, Khan TM, Alrasheedy A, Hassali MA, Aljadhey H. Community pharmacists' knowledge, behaviors and experiences about adverse drug reaction reporting in Saudi Arabia. Saudi Pharm. 2014; 22(5): 411-418.

10. Bawazir SA. Attitude of community pharmacists in Saudi Arabia towards adverse drug reaction reporting. Saudi Pharm J. 2006; 14(1): 75-83.
11. Khan TM. Community pharmacists' knowledge and perceptions about adverse drug reactions and barriers towards their reporting in Eastern region, Alahsa, Saudi Arabia. Ther Adv Drug Saf. 2013 ; 4: 45-51

12. Aljadhey H, Mahmoud MA, Alshammari TM, Al-Dhaeefi $M$, Le Louet H, Perez-Gutthann S, Pitts PJ. A qualitative exploration of the major challenges facing pharmacovigilance in Saudi Arabia. Saudi Med J. 2015 ; 36(9): 1097-1102

13. Bateman DN, Sanders GL, Rawlins MD. Attitudes to adverse drug reaction reporting in the Northern Region. Br J Clin Pharmacol. 1992; 34(5): 421-426.

14. Belton KJ, European Pharmacovigilance Research Group. Attitude survey of adverse drug-reaction reporting by health care professionals across the European Union. Eur J Clin Pharmacol. 1997; 52(6): 423-427.

15. Grootheest V. Attitudinal survey of voluntary reporting of adverse drug reactions. $\mathrm{Br} J$ Clin Pharmacol. 1999; 48(4): 623-627.

16. Belton KJ, Lewis SC, Payne S, Rawlins MD, Wood SM. Attitudinal survey of adverse drug reaction reporting by medical practitioners in the United Kingdom [see comments]. Br J Clin Pharmacol. 1995; 39(3): 223-226.

17. Williams $D$, Feely J. Underreporting of adverse drug reactions: attitudes of Irish doctors. Ir J Med Sci. 1999; 168(4): 257-261.

18. Bäckström M, Mjörndal T, Dahlqvist R, Nordkvist-Olsson $T$. Attitudes to reporting adverse drug reactions in northern Sweden. Eur J Clin Pharmacol. 2000; 56(9-10): 729-732.

19. Abdel-Latif MM, Abdel-Wahab BA. Knowledge and awareness of adverse drug reactions and pharmacovigilance practices among healthcare professionals in Al-Madinah Al-Munawwarah, Kingdom of Saudi Arabia. Saudi Pharm J. 2015; 23(2): 154-161.

20. Alshammari TM, Alamri KK, Ghawa YA, Alohali NF, Abualkol SA, Aljadhey HS. Knowledge and attitude of health-care professionals in hospitals towards pharmacovigilance in Saudi Arabia. Int J Clin Pharm. 2015; 37(6): 1104-1110.

21. Hanafi S, Torkamandi $H$, Hayatshahi A, Gholami K, Shahmirzadi NA, Javadi MR. An educational intervention to improve nurses' knowledge, attitude, and practice toward reporting of adverse drug reactions. . Iran J Nurs Midwifery Res. 2014; 19(1): 101-106. 